\title{
TEACHING ENGLISH AS A FOREIGN LANGUAGE IN INDONESIA: A GUIDELINE FOR VOCABULARY INSTRUCTION
}

\author{
Sudarman Sudarman ${ }^{1}$, Sunarti Sunarti ${ }^{2}$, Elsa Widya Hapasari ${ }^{3}$ \\ ${ }^{1,2}$ Universitas Muhammadiyah Kalimantan Timur \\ ${ }^{3}$ Universitas Kutai Kartanegara \\ Email: sud520@umkt.ac.id
}

\begin{abstract}
This article aims to provide some guidelines for teachers on how to conduct vocabulary instruction in their class because one of the main issues faced by Indonesian students recently is the lack of vocabulary knowledge that affects their English proficiency. Some studies showed that Indonesian students did not even know most of essential words in English, known as high frequency words. As a result, they may struggle to use the language in communication. Therefore, English teachers need to focus on helping students develop their vocabulary knowledge by teaching new words based on students' need and introducing some vocabulary learning strategies that they can use to learn unknown words on their own at home. In order to provide a guideline for vocabulary instruction, this paper reviewed studies related to vocabulary knowledge, English proficiency, and vocabulary instruction in Indonesian context. The result of this study provides a guideline that could help teachers improve their students' vocabulary knowledge in teaching unknown words and vocabulary learning strategies. This paper also suggests English teachers to conduct their own research to determine which strategies work best for their students, so students can apply that strategies to learn unknown words autonomously.
\end{abstract}

Keywords: Vocabulary Knowledge, Vocabulary Instruction, Vocabulary Size And Depth.

This work is licensed under Creative Commons Attribution License 4.0 CC-BY International license

\section{Introduction}

The vocabulary knowledge of Indonesian students has become the concern of researchers in Indonesia recently. Some research shows that Indonesian students are lack of vocabulary knowledge, both breadth and depth. The lack of vocabulary knowledge reflects the English proficiency since vocabulary is an effective tool to predict the language proficiency (Lee, 2011). The more words that the students know, the more likely they will be able to perform the language effectively. If students have a very limited number of vocabulary, they may find it difficult to use the language effectively. On the other hand, if they possess sufficient vocabulary, they could easily express their thoughts during communication.

Some studies revealed that Indonesian students had insufficient vocabulary knowledge as shown by Nurweni and Read (1999), Kurniawan (2017), and Sudarman and Chinokul (2018). 
Nurweni and Read (1999) conducted a study to measure the first-year university students' vocabulary knowledge and figured out that they only knew around 1.226 words in English, which was below the threshold of 3.000 word families. The study from Kurniawan (2017) found that even English department students had a very low vocabulary size, which was approximately 1.400 word families. The results were in line with the study from Sudarman and Chinokul (2018) showing that the first-year university students majoring in English Education knew only about 1.273 word families. It shows that Indonesian students knew less than 3.000 word families that becomes the threshold in order to perform the language for basic daily conversation.

Nation (2006) suggests that in order perform the language effectively, we need approximately 2.000 to 3.000 word families from high frequency word list. The list consists of words that occur the most frequently in English in any situations or contexts. These are the words that everyone must learn in order to use English because these words cover most of the running texts, either oral or written texts.

According to the studies mentioned before, Indonesian students are lack of vocabulary knowledge. They did not even know the 3.000 of high frequency words, which are the most essential words in English. Consequently, they may not be able to perform the language effectively. As shown by a survey conducted by English First, the English Proficiency Index (EPI) of Indonesia showed a declining trend each year. The English Proficiency Index of Indonesia during 2013 to 2016 was on moderate proficiency level. While during 2017 to 2021, the EPI of Indonesia declined to the band of low proficiency. Even in 2021, Indonesia ranks 80 out of 112 countries around the world.

The low English proficiency could be affected by many factors, and one of them could be the lack of vocabulary knowledge. According to Ivone (2005), the English proficiency in Indonesia was very low due to the lack of vocabulary size. Kweldju (2005) even stated that vocabulary is the single source of problem in learning English. Therefore, she suggested that in order to improve the English proficiency, teachers need to focus on helping students improve their vocabulary knowledge. It is assumed that improving students' vocabulary knowledge could also improve their proficiency.

To overcome the issues as mentioned above, this study aimed to conduct a review paper that provides insights about vocabulary instructions. This paper hopefully could assist English teachers in Indonesia to improve their students' vocabulary knowledge, either size or depth. Consequently, the implementation of the principles of vocabulary instruction provided in this paper could also affect to improve Indonesian students' English proficiency as the main goal of any English instruction.

\section{Method}

This study was a systematic review that employed Preferred Reporting Items for Systematic Reviews and Meta-analyses. The study began by searching related papers from Google Scholar by using keywords 'vocabulary knowledge', 'vocabulary size', 'vocabulary instruction', 'vocabulary depth', 'vocabulary learning strategies', and 'Indonesian's English proficiency' in Indonesian contexts. To support the theoretical review, this study also used some books related to principles of teaching vocabulary and vocabulary learning strategies. All the literatures available in full text were downloaded and collected into a computer file. Then, the 
papers were screened to figure out the paper that was related and needed on this study. All the papers and books were classified based on their topics such as vocabulary instruction, vocabulary knowledge specified into size and depth, English proficiency index in Indonesia, vocabulary learning strategies, and so on. The literatures then were analyzed to develop the rationale and the results of this study, which was a guideline for vocabulary instruction.

\section{Findings and Discussions}

\subsection{Roles of Vocabulary Knowledge in Language Acquisition}

Vocabulary is one of the knowledge areas in language that plays a huge role for learners in acquiring a language (Cameron, 2001). Therefore, it is often viewed as a critical tool for second language learners, meaning that knowing only limited essential vocabulary could end up with a failure in communication. In addition, Schmitt (2000) emphasizes that "lexical knowledge is central to communicative competence and to the acquisition of a second language."

On the other hand, Nation (2001) states that vocabulary knowledge and language use have a complementary relationship. Having a sufficient vocabulary knowledge enables an effective language use, and using a language could increase the knowledge of the vocabulary itself. Knowing very few essential words will restrict us from expressing our thougths through a communication. On the other hand, using the language, especially while reading and listening, could also help improve our vocabulary knowledge through incidental learning.

Researchers such as Laufer and Nation (1999), Read (2000), and Nation and Meara (2002) believe that it is essential for second language learners to acquire adequate vocabulary for successful language use because without an extensive vocabulary, we cannot use the structures and functions that we may have learned for comprehensible communication. It is in line with Wilkins (1972) who believes that understanding a good grammatical rules will not be meaningful if we do not have a good understanding on words. He states that "...without grammar very little can be conveyed, without vocabulary nothing can be conveyed."

According to the description above, it can be concluded that vocabulary has an essential role in language acquisition. It means that during the process of language learning, a learner need to take vocabulary aqcuisition into account. Lacking of vocabulary knowledge could affect the failure of using language in communication. Meara (1980) even highlighted that vocabulary is the learners' single source of problem in learning a second language. Thus, Kweldju (2005) suggests that the solution lies on the good handling of vocabulary. It emphasizes the important roles of teachers to introduce new words and learning strategies for students in order to achieve a successful language learning.

\subsection{Vocabulary Knowledge}

Vocabulary knowledge refers to how well we understand about words that include various kinds of lexical knowledge such as pronunciation, spelling, morphology, words' syntactic and semantic relationship with other words, which involve the knowledge about antonym, synonym, hyponym, and collocational meanings. In short, Nation (2001) concludes that there are three aspects of vocabulary that we need to concern about while learning new words, namely form, meaning, and use. The aspect of form refers to the understanding of written and spoken form of words, which includes the spelling and pronunciation of the words. The 
aspect of meaning includes the understanding of the literal meaning of the words as well as their contextual meanings, while the aspect of use reflects the understanding of how the words are used in approprite contexts.

Only understanding the meaning or the words does not provide a sufficient knowledge to use the word in appropriate contexts during communication. We need to learn more than just a literal meaning of words. Nation (2005) further explains the nine aspects of vocabulary knowledge, namely the knowledge of the spoken form of the words, the written form of the words, the word parts, the link between a particular form and a meaning, the concepts of a word may have and the item it can refer to, the vocabulary that is associated with the word, the words' grammatical functions, the words' collocations, and the words' register and frequency. He suggests that these aspects are required while learning new words.

Essentially, there are two dimension of vocabulary knowledge namely the depth and the breadth of the vocabulary. The depth of the vocabulary knowledge simply refers to how well words are known. Developing the depth of the vocabulary knowledge involves a deep study of aspects of the word itself such as spelling, pronunciation, derivations and inflections, meaning senses, semantic associations, collocations, and grammatical functions. Understanding more about particular words will enable us to use the words in appropriate contexts.

On the other hand, the other dimensions of vocabulary knowledge is the breadth of vocabulary knowledge, which is also known as the vocabulary size. The vocabulary size refers to the number of words that we know. Vocabulary breadth is normally determined by the degree to which learners are able to relate the form and meaning of a word. As mentioned earlier, vocabulary size determines the performance of using the language in communication. The more vocabulary size we possess, the more likely we are able to use the language effectively. Unlike the depth of the vocabulary knowledge, vocabulary size is considered as the easier dimension to be measured. We can accumulate the number of vocabulary that we possess by administering Vocabulary Size Tests or Vocabulary Levels Tests.

Some studies have been conducted to measure the relationship between the vocabulary size and vocabulary depth towards the English proficiency. Researchers even studied which of the two dimensions of vocabulary knowledge have a superior correlation with the language performance. Although vocabulary depth showed a stronger correlation with the proficiency, the vocabulary size and depth have been proven to have significant correlations with the learners' language performance (Akbarian, 2010). A study from Mohammadi and Afshar (2016) also revealed that veocabulary size and vocabulary depth had a positive correlation. It means that learners with high vocabulary size tend to have high vocabulary depth and vice versa. The results suggest that to measure learners' vocabulary knowledge, we can only employ one of the two dimensions. It is not always necessary to measure both dimensions in order to know the level of knowledge that learners have about vocabulary.

\subsection{Words Needed to Perform the Language Effectively}

One critical factor to consider when determining the breadth of the vocabulary required to perform the language is the amount of text coverage required to achieve appropriate comprehension without the aid of dictionaries or translation software. In other words, we should be able to determine the maximum amount of foreign language that may be accepted in texts 
without impairing comprehension. The percentage of running words in a text that are recognized by readers is called text coverage.

Using a fictional text, $\mathrm{Hu}$ and Nation (2000) investigated the relationship between text coverage and reading comprehension for native English speakers. They discovered that no one obtained sufficient comprehension from an $80 \%$ coverage text. When they used a text that covered $90 \%$ of the subjects, only a tiny percentage of individuals achieved satisfactory comprehension. With $95 \%$ coverage or fewer than one unknown word in every 20 running words, more participants obtained adequate comprehension, and with $100 \%$ coverage of the text, the majority of subjects gained adequate knowledge. A reasonable metric was discovered when a regression model was applied to the study's data. According to the computation, 98\% text coverage would be required to obtain adequate comprehension from reading the material. This means that only one out of every 50 running words must be unfamiliar to readers. Laufer and Ravenhorst-Kalovski (2010), on the other hand, propose two thresholds: an optimal and a minimal. The optimal one is to be familiar with 8,000 word families, which provides $98 \%$ coverage, including proper nouns. The bare minimum is between 4,000 and 5,000 word families to cover $95 \%$ of the vocabulary, including proper nouns.

Nation (2006) discovered that at a text coverage level of $98 \%$, readers require between 8,000 and 9,000 word families to obtain acceptable comprehension of written texts without the use of helping comprehension tools, and between 6,000 and 7,000 word families for spoken texts. It implies that readers should be familiar with all of the high frequency words, which comprise 2,000 word families, as well as the mid frequency words, which comprise 7,000 word families. On the other hand, Adolphs and Schmitt (2003) assert that participants in basic everyday oral communication require between 2,000 and 3,000 word families, which are high frequency terms.

\subsection{The Vocabulary Instruction}

As mentioned before, the main source of Indonesian students' single problem in learning English is the lack of vocabulary knowledge that affects their low English proficiency. The scholars suggest that to overcome the issue, teachers need to spend part of their teaching time to focus on helping students develop their vocabulary knowledge, either size or depth. Thus, teachers need to allocate a little bit of their teaching time to introduce some new words to their students. However, since the time allocated for vocabulary teaching is very limited, it is impossible to teach all the new words in the class. Beck, McKeown, and Kucan (2013) assumes that teachers can only explicitly teach around 400 words a year in schools. Consequently, besides teaching students new words, teachers should also focus on teaching strategies for the students to learn those words. The purpose of teaching vocabulary learning strategies (VLS) to the students is that they can apply those strategies to learn the unknown words at home autonomously.

From the previous explanation, we can conclude that there are two main purposes of vocabulary instruction; teaching new words and teaching vocabulary learning strategies. While conducting vocabulary instruction, there are some guidelines that teachers need to take into account, both for teaching unknown words and teaching vocabulary learning strategies. The guidelines are explained as follows; 


\subsubsection{Teaching Unknown Words}

A number of features need to be considered while teaching unknown words to the learners, such as the words to focus on, the selection of words, and what aspects of words to learn. Each aspect is described as follows:

\section{a. Words to Focus on}

Nation (2006) developed a list of vocabulary consisting of fourteen levels sorted based on their frequency of occurrence. Each level consists of 1.000 words sorted from the most frequently used to the least frequently used words. Level 1 to Level 3 are the most frequently used words in English called high frequency words. Then, the $4^{\text {th }}$ level to $9^{\text {th }}$ level are classified as mid frequency words, and the $10^{\text {th }}$ level to the $14^{\text {th }}$ level are classified as low frequency words. These are the least frequently used vocabulary in English. Another list that is not included in Nation's list is the academic word list (AWL) developed by Coxhead (2000).

From those lists, it is necessary to determine what learners should really focus on. This is a very crucial step that need a deep analysis about what vocabulary that the learners do need for their own benefit. Nation (2008) emphasizes that not all words are worthy to learn. The principle lying behind the concept of selecting words based on needs is called cost / benefit principle (Nation, 2013).

In order to know what vocabulary that learners must learn, teachers may need to administer a test by using Vocabulary Levels Test (VLT) developed by . Since it is used as a diagnostic test, the test should be administered before teachers start their vocabulary development program. The results of the test will not only give information about what levels that learns need to focus on but also estimates the number of vocabulary size possessed by the learners.

To begin, students should concentrate on high frequency words, which comprise 2,000 to 3,000 word families (Nation, 2013). This is fair given the prominence of the 3,000 words in all texts and situations in which the language is employed. They even cover $80 \%$ of running words in the majority of written texts and $90 \%$ of running words in spoken communications. This means that they will appear eight times for every ten words read aloud and nine times for every ten words spoken. It implies that if students master those terms, they would be able to speak effectively in ordinary conversation and will have no difficulty reading simple novels such as story books. In case of classroom instruction, teachers must devote additional time to teaching these word levels.

Once students have learned the 3,000 most often used terms, they must advance to the subsequent vocabulary levels. If students choose to pursue academic studies, they must become familiar with the academic vocabulary contained in the AWL, which consists of 570 word families. These words encompass around $10 \%$ of the running terms in academic writings. They will assist pupils in navigating English-language reading materials such as textbooks and articles.

For people who are not intending to pursue academic studies in English but wish to acquire the language in order to communicate, watch films and television programs, or read books or magazines, they must therefore master mid frequency words. They comprise 7,000 word families drawn from the British National Corpus's $3^{\text {rd }}$ to $9^{\text {th }} 1,000$-word lists. They are rather large in size, but they are really useful and valuable because they cover around $10 \%$ of the running words. Along with mastery of the high frequency words, learners will have a working knowledge of 
9,000 word families at this stage. The number will cover $98 \%$ of the running words in the most of literature, which eliminates the need for learners to use a dictionary while reading.

The remaining vocabulary levels include words with a low frequency of occurrence and technical terms. In essence, learners do not need to pay close attention to these two levels because they are rarely employed. Apart from that, they are quite tough to master due to their large size, over 100,000 word families. However, for people pursuing academic study in a specific field such as Applied Linguistics, Botany, or Architecture, it will be vital for them to get familiar with the subject area's technical terms.

\section{b. Selection of Words}

After determining the vocabulary level on which students should focus, teachers must decide the words from that level to teach their students. Selecting the words for vocabulary instruction can be challenging, and each instructor may have a unique method for doing so. Even if some experts advocate for one method of word selection over another, there is no evidence that one method is superior to another. As a result, in many circumstances, the classroom teachers choose the vocabulary words to teach their students (Rustand, 2016).

One method to select words for vocabulary instruction is picking the unknown words from reading passages, especially in reading class. Teachers need to provide a reading passage for each student. With the reading passage, teachers will ask students to identify any unfamiliar words in the passage. The words chosen by the students will serve as the focus of their vocabulary instruction. Once the words are chosen, teachers can start teaching those words by using vocabulary learning strategies.

\section{c. Aspects of Words Needed to Learn}

Teachers should pay attention on three components of vocabulary knowledge when learning new words namely form, meaning, and use. Nation (2005) further mentions nine aspects of vocabulary knowledge to be involved in vocabulary instruction including knowledge of the spoken form of the words, the written form of the words, the word parts, the relationship between a particular form and a meaning, the concepts a word may have and the item to which it may refer, the vocabulary associated with the word, the words' grammatical functions, the words' collocations, and the words' register and frequency. He argues that these characteristics are necessary while learning new words.

\subsubsection{Teaching Vocabulary Learning Strategies (VLS)}

Effective vocabulary acquisition practices, according to Shen (2003), should be included into the vocabulary learning process. This suggests that solutions for teaching vocabulary should not be overly teacher-centered. Teachers should create opportunities for students to actively participate in their own language learning. On the other hand, Sökmen (1997) noted that "it is impossible for students to acquire all the vocabulary they require in the classroom," and thus teachers must assist students in dealing with unfamiliar words on their own through the introduction of strategies or techniques. By having a variety of strategies available, learners can freely choose the ones that they believe would work best for them to expand their vocabulary or increase their knowledge, particularly while they are not in the classroom.

Introducing the VLS to the students could be done by involving them to use the strategies while learning new words in the class. The strategies to be taught are generally classified into 
two; discovery strategies and consolidation strategies (Schmitt, 1997). Discovery strategies are strategies used to learn new words when met for the first time, and consolidation strategies are used when learners meet the words again for retrieval, so the words would be anchored in learners' long term memory.

A number of discovery strategies that teachers can apply such as analyzing parts of speech, analyzing affixes and roots, checking for L1 cognates, analyzing any available pictures or gestures, guessing from textual contexts, using bilingual dictionary, using monolingual dictionary, using word lists, using flash cards, or even asking for help from teachers or classmate for particular words' meaning. Each strategy may work differently on each student. Therefore, teachers need to introduce as many strategies as possible, so learners can pick the one that work best for them. After knowing the surface of the new words, teachers need to provide some different strategies in order to retain the words in the students' memory through consolidation strategies.

A bunch of consolidation strategies can be introduced to the learners such as studying and practicing the meaning in a group, teachers check students' flash cards or word lists for accuracy, and interacting with native speakers. These activities should be done collectively by the students. other strategies such as studying words with pictorial representation of its meaning, connecting the words with their synonyms and antonyms, using semantic maps, using 'scales' for gradable adjectives, peg method, loci method, using new words in sentences, grouping words together within a storyline, studying the spelling of words, studying the sounds of words, saying new words aloud when learning, remembering affixes and roots, remembering parts of speech, paraphrasing words' meaning, using cognates in study, learning the words of an idiom together, singing physical action when learning words, and using semantic feature grids can also be employed. Some cognitive strategies such as using verbal repetition, using written repetition, using word lists, using flash cards, taking notes in class, using the vocabulary section in your textbooks, listening to tape of word lists, putting English labels on physical objects, and keeping a vocabulary notebook could also benefit students from knowing the words more deeply.

Teachers are suggested to vary the VLS every time they teach vocabulary. The more VLS they know; the more options they have to learn new words. The vocabulary instruction would be even more interesting for learners because they are exposed a large number of different activities every time they learn new words. So, it would be easier for them to pick the ones that they really love or the ones that work best for them.

\section{Conclusions and Suggestions}

\subsection{Conclusions}

The lack of vocabulary knowledge has become the main problem of Indonesian students in learning English. Some studies revealed that Indonesian students possess a very limited number of vocabulary that could become the main source of their low English proficiency. Thus, English teachers need to also concern on helping students develop their vocabulary knowledge, both depth and breadth, by determining the level of vocabulary that they need to focus on and introducing a number of vocabulary learning strategies. Only focusing on teaching new words will not be really helpful for the students to boost their vocabulary knowledge since the time spent in the class is very limited. Therefore, teachers should also introduce some strategies to 
learn the unknown words, so they can employ the strategies to learn vocabulary on their own after the class.

To overcome this issue, this study has developed a guideline based on research and literature review to be used by English teachers, especially in Indonesia, to assist their students develop their students' vocabulary knowledge, both size and depth. The guideline covered some aspects and principles that teachers need to know before their plan their vocabulary instruction or students' vocabulary development program, include guidelines in teaching new words as well as teaching vocabulary learning strategies.

\subsection{Suggestions}

Since the curriculum adopted in Indonesia does not specifically require vocabulary instruction at schools, teachers cannot conduct the full class only by teaching vocabulary deliberately. The concern of the curriculum is in the development of the four skills in language namely speaking, writing, reading, and listening. The only way for teachers to spare their time for teaching vocabulary is to integrate the vocabulary instruction with the instruction of the four skills, especially reading and listening. Teachers could begin their reading and listening class by introducing some unknown words related to the task that they are going to do. Teachers should also observe the students' vocabulary development regularly to make sure that they really work on it and provide feedbacks if necessary. On the other hand, teachers can also conduct research to figure out which strategies work the best for students, so students can stick on using the strategies to effectively improve their vocabulary knowledge. In addition, the guideline for vocabulary instruction in this paper may be developed based on research, but a future study needs to be conducted to measure its effectiveness in the real circumstances.

\section{REFERENCES}

Adolphs, S., \& Schmitt, N. (2003). Lexical coverage of spoken discourse. Applied linguistics, 24(4), 425-438. doi:https://doi.org/10.1093/applin/24.4.425

Akbarian, I. h. (2010). The relationship between vocabulary size and depth for ESP/EAP learners. System, 38(3), 391-401.

Beck, I. L., McKeown, M. G., \& Kucan, L. (2013). Bringing words to life: Robust vocabulary instruction: Guilford Press.

Cameron, L. (2001). Teaching languages to young learners: Ernst Klett Sprachen.

Coxhead, A. (2000). A new academic word list. TESOL Quarterly, 34(2), 213-238. doi:10.2307/3587951

Hu, H., \& Nation, P. (2000). What vocabulary size is needed to read unsimplified texts. Reading in a foreign language, 8, 689-696.

Ivone, F. M. (2005). Teaching English as a foreign language in Indonesia: The urge to improve classroom vocabulary instruction. TEFLIN journal, 16(2), 195-208. 
Kurniawan, I. (2017). Assessing English students vocabulary size of Lampung State Islamic University. Humaniora, 8(4), 381-390. doi:https://doi.org/10.21512/humaniora.v8i4.3909

Kweldju, S. (2005). Lexically-based language teaching: Metaphor for enhancing learning. Indonesian JELT, 1(2), 52-65.

Laufer, B., \& Nation, P. (1999). A vocabulary-size test of controlled productive ability. Language Testing, 16(1), 33-51.

Laufer, B., \& Ravenhorst-Kalovski, G. C. (2010). Lexical threshold revisited: Lexical text coverage, learners' vocabulary size and reading comprehension. Reading in a foreign language, 22(1), 15.

Lee, J. (2011). Size matters: Early vocabulary as a predictor of language and literacy competence. Applied Psycholinguistics, 32(1), 69-92.

Meara, P. (1980). Vocabulary acquisition: A neglected aspect of language learning. Language Teaching, 13(3-4), 221-246.

Mohammadi, S. M., \& Afshar, N. B. (2016). Vocabulary knowledge learning and reading comprehension performance: which one is superior-breadth or depth?

Nation, I. (2005). Teaching and learning vocabulary Handbook of research in second language teaching and learning (pp. 605-620): Routledge.

Nation, I. S. P. (2001). Learning vocabulary in another language: Ernst Klett Sprachen.

Nation, I. S. P. (2006). How large a vocabulary is needed for reading and listening? Canadian modern language review, 63(1), 59-82.

Nation, I. S. P. (2008). Teaching vocabulary: Strategies and techniques. Boston: Heinle Cengage Learning.

Nation, I. S. P. (2013). What should every EFL teacher know? : Compass Publishing Seoul.

Nation, I. S. P., \& Meara, P. (2002). Vocabulary. An introduction to applied linguistics, 35-54.

Nurhemida. (2007). The relationship between morphological awareness and English vocabulary knowledge of Indonesian senior high school students. (Master Unpublished master's thesis), The University of Queensland, St Lucia.

Nurweni, A., \& Read, J. (1999). The English vocabulary knowledge of Indonesian university students. English for Specific Purposes, 18(2), 161-175.

Read, J. (2000). Assessing vocabulary: Cambridge University Press.

Rustand, A. (2016). How Vocabulary Word Selection, Instructional Strategies, And Assessments Affect Student Retention Of Newly Learned Words. 
Schmitt, N. (1997). Vocabulary learning strategies. Vocabulary: Description, acquisition and pedagogy, 199227.

Schmitt, N. (2000). Vocabulary in language teaching: Ernst Klett Sprachen.

Schmitt, N., Schmitt, D., \& Clapham, C. (2001). Developing and exploring the behaviour of two new versions of the Vocabulary Levels Test. Language Testing, 18(1), 55-88. doi:doi:10.1177/026553220101800103

Shen, W.-W. (2003). Current trends of vocabulary teaching and learning strategies for EFL settings. Feng chia journal of Humanities and social sciences, 7(1), 187-224.

Sökmen, A. J. (1997). Current trends in teaching second language vocabulary. Readings in Methodology, 152.

Sudarman, S., \& Chinokul, S. (2018). The English vocabulary size and level of English department students at Kutai Kartanegara University. ETERNAL (English, Teaching, Learning, and Research Journal), 4(1), 1-15.

Wilkins, D. A. (1972). Linguistics in language teaching: E. Arnold, 1973. 